\title{
VIOLETA PARRA EN PLURAL
}

\author{
Marisol García C.
}

Periodista

\begin{abstract}
RESUMEN: Este ensayo describe la ambición, la extensión y el rigor de la investigación que Violeta Parra llevó adelante en busca de las raíces del arte popular chileno, en una etapa de indagación que la artista consideró fundamental en su formación como autora. El trabajo en terreno le mostró a la chilena el valor de una tradición, a la cual decidió en adelante tributar y aportar, sin buscar darle a su propio trabajo un énfasis individual, disociado de ese cauce colectivo. Violeta Parra entendió su voz enlazada a las de cantoras de campo y poetas populares, e incluso en su filosofía y opciones de vida latían las lecciones aprendidas de esos maestros, a los que nunca dejó de ver desde el respeto, incluso después de asentar su propio prestigio. Para la autora de este ensayo, ningún otro creador chileno parece haber definido su arte tan firmemente junto a las voces de otros.
\end{abstract}

Palabras clave: Violeta Parra, poesía popular, folclor chileno, décimas, investigación en terreno, canto a lo poeta.

\section{VIOLETA PARRA, PLURAL}

ABstract: This essay describes the ambitiousness, scope and rigour of the research Violeta Parra carried out as she sought the roots of Chilean popular art, an effort she considered vital to her development as a songwriter. Her field research showed her the value of a tradition, which she decided thereafter to pay tribute and contribute to without attempting to give her own work any individual stamp

Marisol García C. Periodista de la Universidad Diego Portales. Especialista en música popular chilena. Es autora de los libros Canción valiente (2013) y Llora, corazón (2017), y estuvo a cargo de la preparación de Violeta Parra en sus palabras. Entrevistas (1954-1967) (2017). Email: solgarcia@yahoo.com. 
that would set it apart from this collective endeavour. For Violeta Parra, her own voice was always mingled with those of country singers and popular poets, and even her life choices and philosophy were underlain by the lessons learned from these masters, whom she never ceased to regard with respect even once her own reputation was firmly established. The author of this study knows of no other Chilean artist who has defined their art so firmly in relation to the voices of others.

Keywords: Violeta Parra, popular poetry, Chilean folklore, décima verse form, field research, canto a lo poeta.

U

n mapa dibujado a dos páginas abre el libro más valioso publicado en los últimos meses sobre Violeta Parra. Muestra un área chilena acotada, apenas el cruce de las regiones del Biobío y de La Araucanía; San Carlos arriba y Rucahue junto al margen inferior. Círculos de tres tamaños diferencian el paso de la creadora chilena por esas ciudades y pueblos: en Concepción y Lautaro investigó y vivió; San Carlos, Chillán y San Fabián de Alico la acogieron para su residencia estable; y hay cuatro pueblos pequeños marcados como focos de exclusiva investigación: Cinco Manzanos, Labranza, Millelche y Rucahue, y la comunidad López Quilapan.

El mapa es significativo porque hasta ahora los puntos considerados para explicar el trabajo de recopilación de Violeta Parra se habían fijado sobre todo en el Valle Central. Se ha escrito sobre el paso de la creadora por Alto Jahuel, Barrancas, San Bernardo, Puente Alto, Curacaví, San Javier, Carrascal, Rancagua, Los Vilos, y sectores de las provincias del Maule y Valparaíso; y estudiado su esfuerzo desde los años cincuenta en la búsqueda de canto campesino y poesía popular. Aquel trabajo centrado en la precordillera cercana a Santiago y el sector costero forjó de modo fundamental su posterior obra de autora.

- He buscado el folclor chileno en cada rincón del campo, de los pueblos, de las montañas; he grabado cerca de doscientos cantos — cuenta ella en entrevista de 1964 con un semanario suizo-. Estuvo bien: descubrí a mi pueblo. Desde entonces ya no tengo complejos, ni problemas ni preocupaciones. ${ }^{1}$

${ }^{1}$ Marisol García ed., Violeta Parra en sus palabras. Entrevistas (1954-1967) (Santiago: CIP UDP/Catalonia, 2017), 79. 
Ella misma destacaba que al hacer su trabajo de recopiladora dejaba un registro de sus descubrimientos "absolutamente puro, sin cambiarle ni una coma ni un punto". Apoyaba su método, sobre todo, en el esfuerzo a solas: llegar por los propios medios a un lugar apartado en el que se adivinara riqueza tradicional; cuaderno y lápiz en la mano, guitarra al hombro. A veces, su hijo Ángel cargaba por ella una pesada grabadora polaca.

El primer desafío es dar, por datos, con cantoras y poetas alrededor de los fundos. Vencer luego la desconfianza de todos ellos para dejarse entrevistar. Aceptar, a veces, un vaso de licor o un cocido de carne. La investigación en terreno era también un ejercicio de seducción y de cercanía, en el que rápidamente se hacía evidente el interés auténtico de la visitante por lo que los lugareños pudieran revelarle.

Al fin, grabar ese canto de la tierra a punto de desaparecer.

Más que escuchar los discos de desconocidos, más que leer libros importados, antes de largarse como autora, Violeta Parra prefirió enfrentarse a lo que otros podían enseñarle sobre el oficio y los valores de la tierra. Se conoce ya la relevancia de esa labor de búsqueda - es la escena que, de hecho, abre su biografía en cine Violeta se fue a los cielos, de Andrés Wood (2011) - , pero no tanto el sentido que esos años de viajes, caminatas y conversaciones tuvieron en la definición de su obra y hasta de sus opciones prácticas, que no era para ella la de una artista individual, sino la de una mujer puesta a disposición del arte popular.

Es la paradoja de que uno de los nombres universales de la cultura chilena nunca se haya visto trabajando para sí misma.

Parte de aquella experiencia formativa en los campos nutre uno de los tres libros de su autoría, Cantos folklóricos chilenos. Allí se reproducen diálogos, cantos y fotografías in situ (a cargo de sus prestigiados amigos Sergio Larraín y Sergio Bravo), en una edición que fue publicada recién doce años después de su muerte por Nascimento. ${ }^{2}$

"Sin ser invitada ni esperada, invadió el espacio de esa gente (...) donde aún palpitaba el corazón del Chile auténticamente chileno", ha escrito Gastón Soublette sobre esa labor en terreno. ${ }^{3}$ El académico cree que la tradición del país rural confiaba en que algo así sucediera:

\footnotetext{
${ }^{2}$ Cantos folklóricos chilenos fue reeditado en 2013 por Editorial Ceibo.

${ }^{3}$ Gastón Soublette, "Prólogo", en Violeta Parra, Cantos folklóricos chilenos (Santiago: Editorial Ceibo, 2013), 10.
} 
La prodigiosa memoria de nuestros cantores y cantoras, de nuestros narradores y refraneros, en su mayor parte ya ancianos o a punto de irse con su repertorio a mejor vida (...), en espera de que alguien llamado Violeta Parra entrara sorpresivamente en los humildes hogares de esa gente a sondear su memoria debilitada por lo vivido y lo sufrido en un moderno acontecer que marchaba seguro hacia la masificación y la globalización, en desmedro de esa cultura que hasta entonces había dado sentido e identidad a este país en lo que tiene de más genuinamente nuestro.

El aporte del nuevo libro Violeta Parra en el Wallmapu ${ }^{4}$ resulta significativo porque precisa aún mejor ese esfuerzo de años que hoy se entiende como lo más aleccionador emprendido por la artista en el forjado de su propia obra. No había hasta ahora detalles sobre la investigación hecha por ella en la Región de La Araucanía, específicamente entre comunidades mapuches. Era una tradición que se intuía como importante para ella desde la admiración y el respeto - aparece, patente, en sus canciones "El guillatún" (1966) y "Arauco tiene una pena" (1962)—, pero no desde el contacto personal y sistemático que ahora sabemos también marcó su obra y su propia filosofía.

Cuatro cintas de audio de ochenta minutos de duración, guardadas en la Mediateca de la Universidad de Chile desde 1958, largaron hace un par de años la investigación de la especialista en literatura y poesía chilena Paula Miranda (PUC), quien escuchó allí las entrevistas hechas por Violeta Parra a siete ülkantufes (cantores mapuches), un cantor de la zona y seis cantoras, además de treintaiséis de sus cantos en mapudungun y sus palabras. Son grabaciones con data de 1957 y 1958, y que no se explica uno por qué no se habían considerado antes en los estudios biográficos ni en la edición de sus obras.

"Encontramos aquel eslabón que la conecta con el mundo mapuche, en el mismo nivel de influencia fundamental que ella recibió de la cueca, la tonada, el canto a lo poeta o la sirilla", 5 se afirma en la presentación del libro. Y continúa:

${ }^{4}$ Paula Miranda, Elisa Loncon y Allison Ramay, Violeta Parra en el Wallmapu. Su encuentro con el canto mapuche (Santiago: Pehuén, 2017).

5 Ibídem, 15. 
Así, podemos afirmar hoy, con absoluta certeza, que una de las artistas más admiradas en Chile y el mundo, por su capacidad para interpelar nuestras emociones, visiones y experiencias, también nutrió su obra de la cultura mapuche. Es más, por las fechas en que esas grabaciones fueron realizadas es probable que esa conexión contribuyese a gatillar en ella el despliegue de su etapa más creativa y experimental, bajo una impronta única y radical, comenzando con "El gavilán", las anticuecas y sus décimas autobiográficas. ${ }^{6}$

La investigación completada por las académicas Paula Miranda, Elisa Loncon y Allison Ramay — publicada a principios de 2017 por editorial Pehuén - ilumina facetas asombrosas de Violeta Parra como mujer que anhelaba sentidos nuevos para sus esfuerzos y zozobras. Ángel Parra, su hijo, saludó la publicación por cómo demuestra que el trabajo de su madre en territorio mapuche "la llevó a comprender que existía otro mundo, otra cultura, otro idioma, otra religión, otra tradición". ${ }^{7}$

No hay modo de medir realmente qué tan profunda fue la transformación que activó en Violeta Parra su tiempo junto a los mapuches. Revisar, sin embargo, el método de su conversación con ellos es revelador de su rigor como investigadora y creadora, y por cierto entrega pistas de cómo el trabajo en terreno pasaba a su cancionero.

A falta de un trabajo que detalle las circunstancias de composición de cada una de las canciones de Violeta Parra — ¿quién podría hacerlo?-, a estas alturas de su centenario, de homenajes y coloquios entre especialistas, de documentales y hasta de cuadros coreográficos en televisión, atisbar nuevas claves para comprender la personalidad contenida sin alarde en esas piezas sorprende aún y confirma otra vez la altura de su legado.

"Incluido el que habla, nadie sabe quién es Violeta Parra". La frase de Nicanor Parra es de $1993,{ }^{8}$ y seguirá vigente sólo si insistimos en dar con una definición cerrada sobre la más atípica de las artistas, aquella que no buscó descollar como voz individual sino que antes orientar su

${ }^{6}$ Ibídem.

${ }^{7}$ Ibídem, contratapa.

${ }^{8}$ María Teresa Cárdenas, "Nicanor Parra: 'Incluido el que habla, nadie sabe quién es Violeta Parra”, en Revista de Libros, El Mercurio, 2 de mayo, 1993. 
expresión personal hacia la fusión con un lenguaje más amplio y mayor que el suyo propio, cual fue el del folclor. Su identidad de autora tomó parte de su esencia haciéndose parte de un colectivo.

La causa de Violeta Parra, superior a ella, fue el arte popular chileno, y a falta de los recursos que le hubiesen permitido entregarse a ésta desde el acomodo de una rutina personal consolidada, decidió ponerse toda ella a disposición. Como en una gesta de alcances que nunca dudó en considerar trascendentes, ubicó a su familia, sus aspiraciones, sus relaciones de afecto y sus decisiones prácticas en línea con ese objetivo mayor.

Fue un ascenso desde su interior a la gente, de ésta a la tradición, desde allí a la creación y al fin a un lugar de encuentro absoluto con los demás.

"Creo que todo artista debe aspirar a tener como meta el fundirse, el fundir su trabajo en el contacto directo con el pueblo", dice en la última entrevista que dio a una radio, cuatro semanas antes de su suicidio. "Yo estoy muy contenta de haber llegado a un punto de mi trabajo en que ya ni siquiera quiero hacer tapicería, ni pintura ni poesía así suelta. Estoy contenta de haber podido levantar la Carpa y trabajar esta vez con elementos vivos, con el público cerquita mío; al cual yo puedo sentir, tocar, hablarle e incorporarlo a mi alma. La fusión del alma del artista con el público es lo que realmente a mi criterio, no sé si me equivoco, es lo que realmente vale en el trabajo de un artista". ${ }^{9}$

$* * * * *$

La singularidad de la voz autoral de Violeta Parra no requiere siquiera defensa, pero no fue algo que ella deliberadamente buscase exponer. Enarbolar las opiniones, causas o enfoques a los que nos ha acostumbrado la prensa cultural en cualquier nota o entrevista a un artista tenía sin cuidado a la autora de "Volver a los 17" (1966).

No era cosa de un ego forzosamente aplacado; ni siquiera de falsa modestia (suficientes recuerdos de quienes la conocieron certifican su bravía y orgullo propio, lo desafiantes de su estampa y su actitud, poco paciente con el titubeo ajeno y consciente de su valor como investigadora). Su distancia de las autodefiniciones artísticas resultaba, más bien, de verse a sí misma en la continuidad de una tradición, con cantoras de-

\footnotetext{
${ }^{9}$ García, Violeta Parra, 113.
} 
lante, detrás y al lado suyo; entre poetas populares dialogantes; inspirada por artesanas silenciosas y escritores atrevidos en su misma lengua.

El alcance actual de su arte universal es, en ese sentido, la retribución justa para quien buscó separar su obra de los límites de su lugar y biografía, y a la vez no temió intrincarse ella misma con un trabajo que se autoimpuso como una misión:

Me enojo con medio mundo para salir adelante, porque todavía ni la décima parte de los chilenos reconoce su folklore, así que tengo que estar batallando casi puerta por puerta y ventana por ventana. Es harto duro todavía, es como si estuviera empezando recién. ${ }^{10}$

La presencia pública de quien dedica su tiempo a la creación es hoy, entre otras cosas, plataforma para distinguir en inamovible primera persona del singular una mirada y un estilo a los que suele dárseles mucha importancia; muchas veces, incluso, acerca de asuntos sobre los que ni siquiera se tiene un filtro especializado ni de avanzada. Muchos protagonistas del mundo cultural opinan de casi todo, y en esa condición de tasadores del entorno son buscados por los medios.

Violeta Parra, en cambio, pocas veces accedió a explicitar sus peculiaridades como autora. No hay siquiera registro de ella hablando de sí misma como una "artista". Fue una elección suya priorizar la fusión de su voz con la de otros muchos.

“... el canto de ustedes / que es el mismo canto. / El canto de todos / que es mi propio canto»", son los hermosos y conocidos versos de cierre de "Gracias a la vida" (1966); frases dedicadas a un grupo amplio y anónimo, que pueden verse hoy como el manifiesto definitivo de quien, al momento de entonarlos, ya planificaba su partida. Dice en una elocuente entrevista de principios de 1966 con la revista chilena Aquí Está:

- No soy más que una humilde cantora que apenas sí sabe hablar. Yo interpreto y el público juzga.

- ¿A qué atribuye usted que toda su familia (hermanos, hijos, sobrinos y esposo) esté dedicada a una rama del arte nacional?

${ }^{10}$ Ibídem, 41. 
¿Un don hereditario? ¿Convivencia? ¿Comprensión? ¿Otra razón?

— Todo el pueblo de Chile es artista. Es él más artista que nadie, y nosotros somos del pueblo. ${ }^{11}$

Recién en enero de 1967, durante la citada última entrevista en radio, ${ }^{12}$ la creadora al fin concede que su obra sí califica como la de una autora:

Yo estoy contenta de considerarme, en estos momentos, como compositora. Creo que las canciones más lindas, las más maduras... Perdónenme que diga canciones lindas habiéndolas hecho yo, pero qué quieren ustedes: yo soy huasa y digo las cosas sencillamente, como las siento. Las canciones más enteras que yo he compuesto son "Gracias a la vida", "Volver a los 17" y el "Run Run se fue pa'l norte". ${ }^{13}$

No se entiende bien a Violeta Parra, entonces, si no es desde esa conciencia suya de estar siendo parte de una comunidad, sin jerarquías ni méritos de distinción. Puede ser un ejercicio interesante, aunque incompleto, buscar en ella códigos que la asocien a un determinado género o escuela artística. Ni siquiera la adherencia a una corriente ideológica, un pensamiento político o un credo — que los hay en su biografía - es tan indicativo de su obra como observar la firme decisión suya por fusionarse con la expresión popular chilena y la tradición que la sostiene.

“¿Qué cosas cree que a la Violeta le molestaban profundamente?", le pregunta María Teresa Cárdenas a Nicanor Parra en la citada entrevista de 1993. "Yo diría que la inautenticidad. Por eso que ella se iba a los barrios", responde su hermano mayor.

Violeta del pueblo fue, de hecho, el título del primer libro que en el mundo consideró su obra como un legado poético propiamente tal, antologado en 1976 en España por Javier Martínez Reverte para editorial Visor.

\footnotetext{
${ }^{11}$ García, Violeta Parra, 90.

${ }^{12}$ En Radio Magallanes, el 1 de enero de 1967.

${ }^{13}$ García, Violeta Parra, 114.
} 
Ni "para" ni "con" ni "a nombre de": del pueblo. Así saluda Pablo de Rokha a su amiga en una de las ediciones para las Décimas:

Es pueblo y dolor popular, complejo y ecuménico en su sencillez de subterráneo, porque el pueblo es complejo, sencillo, tremendo e inmortal, como sus héroes, criado con leche de sangre (...). Saludo a Violeta como una cantora sudamericana de todo lo chileno, chilenísimo y popular, entrañablemente popular, sudado y ensangrentado y su gran enigma, y como a una heroica mujer chilena. $^{14}$

Las representaciones del mundo popular rozan áreas de poder y construcción de identidades colectivas que impiden que "el pueblo se presente a sí mismo", en palabras de Néstor García Canclini; orientadas, según el escritor argentino, a "una invención melancólica de las tradiciones". 15

Creemos asomarnos a las vivencias y expresiones populares en el acercamiento a lo que no son más que sus estereotipos, simplificaciones o adaptaciones de mercado. Es algo especialmente evidente en la música popular, que desde el siglo pasado — encauzada ya, y de modo muy rentable, por la industria discográfica - nos fue entregando por turnos voces y rostros brillantes dispuestos a desalinizar los pulsos originarios de su entorno, para así convertir en éxito la expresión originaria aprendida de otros cuerpos y ánimos —-más sombríos—, incompatibles con la amplificación comercial.

Fue la samba vía Carmen Miranda, el blues según Led Zeppelin, el hip-hop blanco de los Beastie Boys.

El musicólogo chileno Rodrigo Torres destaca, por eso, que Violeta Parra haya podido urdir su propio canto incluso entre la edificación de esos "macrorrelatos identitarios, funcionales a la unificación de comportamientos y a la legitimación de una política cultural estatal", ${ }^{16}$ presentes desde los años treinta en todo el continente pero anclados en nuestro país a las representaciones simbólicas en torno a la hacienda,

${ }^{14}$ Pablo de Rokha, "Violeta y su guitarra", en Violeta Parra, Décimas. Autobiografía en verso (Santiago: Editorial Sudamericana, 1988), 19.

${ }^{15}$ Citado por Rodrigo Torres Alvarado, "Cantar la diferencia. Violeta Parra y la canción chilena”, en Revista Musical Chilena, año LVIII, n. ${ }^{\circ} 201$ (2004), 54.

16 Torres Alvarado, "Cantar la diferencia", 55. 
y al imaginario que transmitió sobre todo la traducción "típica" de la tonada y de la cueca.

Nuestra conclusión es simple: la reivindicación de la diferencia, aquélla del "otro" popular y la suya propia, es una constante del canto de Violeta Parra (...) como espacio de afirmación épica de un sentido de pertenencia negado o ignorado. En ese contexto, Violeta Parra representará una moral del canto; un modelo de interacción de lo rural y lo urbano, de reciclaje de tradiciones vernáculas en la creación artística; un testimonio de soberano ejercicio de su autonomía y de resistencia del mundo popular, enfrentado a una problemática modernización. Desde esta condición será frecuentemente reivindicada como alma mater del movimiento de la Nueva Canción Chilena. Mas, sobre todo, su canto de la diferencia abrió un espacio sensible al reconocimiento de las múltiples identidades que constituyen el país chileno. ${ }^{17}$

Violeta Parra considera aquello de dar a conocer la voz popular "sin cambiarle ni una coma ni un punto" como uno de sus principales aportes. En entrevista de 1961 al diario El Siglo, parece ofuscada con la dedicación de las radios a "machetear" música extranjera ("especialmente norteamericana, sin ofender a Paul Anka", según precisa), así como a "los conjuntos folclóricos que se fabrican en el medio de la Plaza de Armas". ${ }^{18}$ Dice:

Si estos conjuntos nacidos en la ciudad se prepararan con maestros especializados, tendríamos el enorme placer de contar con gente que estaría menos propensa a la estilización, al disfraz en el vestuario, a los gorgoreos en la interpretación y a las sonrisas postizas de los intérpretes en el momento de estar bailando una cueca de los dientes para afuera. ${ }^{19}$

Su obra es eslabón brillante y pulido de una cadena larga y sin fin, de materiales nobles e irreproducibles; a la que ella se ensambla como destino seguro, no sólo para el respeto que busca manifestarles a la tie-

\footnotetext{
${ }^{17}$ Torres Alvarado, "Cantar la diferencia", 69.

18 García, Violeta Parra, 51.

${ }^{19}$ Ibídem.
} 
rra y a la cultura de raíz, sino también para su necesidad expresiva, su curiosidad por el mundo y su ansia de justicia social. A su ética de creadora, hasta cierto punto.

Así, el cancionero de Violeta Parra se afirma en un ensamblaje más amplio de expresión campesina y popular chilena; también en la cosmovisión indígena y en el grito de defensa obrera. Y ella entiende todo aquello como un cauce complejo, diversificado y profundo.

No es el registro por el registro, ni la métrica por la métrica. Es, en verdad, creación personal de nutrición colectiva.

Como "la folclorista más experimental y la vanguardista más tradicional" la describe la académica Paula Miranda. A aquello que rescata le añade el brillo de una voz propia, aunque sin alterar ni maquillar la fuente honda de la que se alimenta. La suya es una obra de riqueza en parte heredada, en el mejor sentido de la idea: no por simple remedo de un saber ajeno, sino por la firmeza de sus raíces. Creación mestiza y “de pureza original" (no individual).

De ahí lo atípico de su método. Fue un camino creativo confiado de la riqueza de las fuentes a las que acudió y, a la vez, una constatación de que nunca se desesperó pese a la limitación de sus pocos recursos.

—Y usted, ¿a qué se dedica? - le preguntó, desdeñosa, la famosa Ester Soré la primera vez que la tuvo al frente. En el comedor de un elegante hotel de Talca se miraban esa noche la sancarlina de pelo largo y pollera tosca con la cantante, actriz y reina de belleza, conocida desde los años treinta en todo Chile como "La Negra Linda".

- Yo soy artista... soy folclorista — respondió Violeta Parra.

-Hummm, no la he escuchado nunca.

-Es lo de menos. Con el tiempo voy a ser mucho más famosa que usted.

El músico e investigador Mario Rojas — quien cita la anécdota en uno de sus libros, como recuerdo directo del guitarrista Alejandro Cano Espínola $-{ }^{20}$ estima que esa noche, en esa puntual insolencia de sobremesa, "Violeta dictó la sentencia de muerte al criollismo". ${ }^{21}$

${ }^{20}$ Mario Rojas, El que sae, sae. Crónica personal de la cueca brava (Santiago: Ocho Libros Editores, 2012), 99.

${ }^{21}$ Ibídem. 
La suya era una soberbia simbólica — de una verdad irrefutable, por lo demás-, que aun frente a pocos testigos contaba ya con la firmeza para marcar una división trascendente entre lo que la bullente industria musical de esos años pretendía instalar como música chilena y la raíz auténtica, dispuesta a defenderse con el peso que le otorgaba la tradición, la cadena pura de la oralidad y la interpretación ajena a los artificios de escenario.

"¡Ay!, cómo se le erizaba la piel a la Violeta cuando escuchaba cantar a Los Huasos Quincheros”, recordaba su hermana Hilda. “ $¡ E s t o s$ impostores!", decía. ${ }^{22}$

Sin ese orgullo, la persistencia del trabajo de Violeta Parra se hubiese perdido en un cauce de simple voluntarismo, incapaz de sostenerse en una industria y una institucionalidad cultural sin cabida entonces (ni ahora) para su estilo, y por las cuales la autora no estuvo dispuesta a dejarse intimidar. Sus juicios musicales eran filudos, incluso al analizar figuras respetadas en el ámbito de la proyección folclórica de su tiempo, como el dúo Rey-Silva, la cantante Margarita Alarcón y el dúo Bascuñán-Del Campo. Estimaba que la proyección del folclor conlleva no sólo el resguardo de un repertorio, sino también un modo de interpretación y la toma de conciencia sobre sus raíces.

Esa obstinación resultó una indudable ventaja cuando quiso sembrarla en la tierra fértil del circuito cultural europeo. Viajó hasta allá por primera vez entre 1955 y 1956 (Varsovia, ciudades de la ex URSS, París, Londres), y de nuevo entre 1962 y 1965. En París y Ginebra vivió sola, con sus hijos y nieta, o con Gilbert Favre, el suizo al que había conocido el día de su cumpleaños de 1960.

Grabaciones en Londres para la BBC; conciertos regulares en la casa ginebrina de madame Grampert, amiga suiza; presentaciones como solista, o junto a sus hijos y Favre; registro de sobre una veintena de canciones (entre composiciones propias y recopiladas en el campo chileno) en los estudios del sello francés Chante du Monde, en París: la agenda profesional de Violeta Parra en Europa fue la de un talento que parecía florecer aún más ante un público curioso y receptivo, frente al que ella desplegaba los frutos de su inventiva y de su previo trabajo en terreno, y para el que ningún esfuerzo le parecía excesivo,

${ }^{22}$ Patricia Bravo y Patricia Štambuk, Violeta Parra. El canto de todos (Santiago: Pehuén, 2011), 82. 
sino la justa parte del trato del cauce que había elegido darle a su existencia.

Es cierto que la perspectiva de desplegar sus arpilleras, óleos y esculturas en un pabellón del Louvre le provocó en algún momento un asombro incrédulo (“ ¿...cómo iba a exponer yo en el Louvre? ¿Yo, que soy la mujer más fea del planeta y que venía de un país pequeño, de Chillán, del último confín del mundo?") ${ }^{23}$, pero quedan pistas que demuestran que también se sentía digna del reconocimiento; que el pabellón Marsan del más famoso museo de Europa era, por qué no, parte de su destino.

"Te prometo que pronto verás ahí dentro una exposición de mis obras", le comentó a Alejandro Jodorowsky cuando llegó por segunda vez a París. "A mí, que soy tan pequeña, ese enorme edificio no me asusta. El Louvre es un cementerio y nosotros estamos vivos. La vida es más poderosa que la muerte". 24

Esa misma ambición era, en cambio, el músculo que se acalambraba con dolor en sus infinitos proyectos frustrados en Chile. El paso de Violeta Parra por Santiago, Concepción, Valparaíso y el Norte Grande es, muchas veces, el registro humillante de portazos, compromisos incumplidos y desprecio. Hubo conquistas puntuales en iniciativas como su fundación del Museo Nacional del Arte Popular y Folclórico Chileno, dependiente de la Universidad de Concepción (1957), su programa "Canta Violeta Parra" para radio Chilena (1954, junto a Ricardo García), sus charlas en universidades o sus exposiciones en las ferias de arte del Parque Forestal, pero también esos mismos espacios fueron escenario de punzantes ninguneos.

“¿Dónde te robaste 'La jardinera'? ¿Quién te va a creer que es tuya?”, recuerda su hija que la emplazó un músico con el que Violeta Parra se topó en un estudio radial. ${ }^{25}$

Mucho antes de que "lo popular" fuese materia de estudio o de rescate, la artista llevaba al salón y al auditorio académico un mundo desconocido, no creado por ella, sino que descubierto en caminatas por campos de Barrancas y pobres casas de adobe de Pirque, en fiestas reli-

${ }^{23}$ Isabel Parra, El libro mayor de Violeta Parra (Madrid: Meridión, 1985), 114.

${ }^{24}$ Alejandro Jodorowsky, El maestro y las magas (Madrid: Ediciones Siruela, 2005), 18.

${ }^{25}$ Isabel Parra, El libro mayor, 47. 
giosas del pueblo nortino de Salamanca y en exploraciones por parajes casi inaccesibles de Chiloé. Consideremos que muchos de los álbumes de Violeta Parra fueron publicándose en paralelo al temprano auge del llamado neofolclor. Para el año 1963 ya estaban formados Los Cuatro Cuartos y Las Cuatro Brujas, y Chile se acomodaba con entusiasmo a esa estilización de la canción chilena coordinada por el productor Camilo Fernández desde el sello Arena. Violeta Parra, sin embargo, insistía en la exploración in situ, resistiendo porfiadamente los códigos de armonización y disposición escénica aún impuestos a las mujeres dedicadas a la música tradicional. Es probable que haya sido ella la primera mujer en tocar guitarrón, un instrumento no sólo complejo en técnica, sino que también rodeado de una serie de exigencias rituales en su fabricación e interpretación, y que por décadas se asoció de modo excluyente a los campesinos hombres.

Incluso con Margot Loyola - amiga y comadre, respetada por Violeta Parra como "intérprete verdadera" del folclor- marcaba la distancia del entorno: "Yo recogí lo que ella no apreció del todo. Ella es mujer de ciudad urbanizada. Yo le doy mayor importancia a la expresión legítima del pueblo". ${ }^{26}$

Las dos se habían hablado por primera vez a principios de los años cincuenta, una noche en la Feria de la Quinta Normal. La investigadora ya era prestigiada entonces por su trabajo en terreno y su labor de maestra en las Escuelas de Temporada de la Universidad de Chile, y quedó impresionada de cómo la audiencia participaba en el estribillo de la guaracha "Tranquilo el perro", en el que Violeta invitaba al público a repetir junto a ella un ladrido. Un “iguau, guau!” las unió para siempre.

\section{$* * * *$}

Se llamaba a sí misma "una plebeya". Incluso cuando su figuración y su experiencia ya la separaban por completo del promedio de músicos locales, las decisiones prácticas en su vida buscaban resguardarle la máxima sencillez.

"El lujo es una porquería", la cita su hija Isabel en El libro mayor de Violeta Parra. "Los seres humanos se consumen sumergidos en problemas caseros". ${ }^{27}$

\footnotetext{
${ }^{26}$ García, Violeta Parra, 58.

${ }^{27}$ Isabel Parra, El libro mayor, 143.
} 
En esa austeridad había una decisión, pero también el pago voluntario de un precio. Su compromiso íntegro con la causa del arte popular la hizo asumir, también, renuncias y privaciones. Su crianza ya le había inscrito la precariedad, pero luego, en su adultez, Violeta Parra vivió ese despojo como parte de un actuar en que asoció el rigor a la falta de adornos, afeites y distracciones materiales. Es esa severidad, por lo demás, la que en parte levantó su cancionero de denuncia y protesta.

La famosa Carpa de La Reina, el lugar que emplazó a su regreso de Europa en avenida Larraín, soñando con un imposible Centro de Arte Popular — allí vivió desde fines de 1965 y allí eligió morir a comienzos de 1967-, era un espacio precario, en el que la artista se reservó un sector con piso de tierra para levantarse una casa de madera extremadamente sencilla. Vivía junto a Gilbert Favre (hasta que él partió a Bolivia, en 1966) y su hija menor, Carmen Luisa. Cuando llovía, todo se convertía en un barrial.

Nicanor Parra conoció el lugar y temió lo peor. "Esta va a ser tu tumba", le advirtió. Ella llegaba de Europa, su prestigio podía consolidarse con los cálculos correctos.

-Nicanor, perdóname tú, que yo vengo del Louvre y me voy al Zanjón de la Aguada, pero es que de ahí yo saco mis energías — se defendió ella entonces-. El nido se hace solo, guachito culebra. El nido se hace solo...28

Por eso, no es posible separar la firmeza en el trabajo de Violeta Parra como investigadora, divulgadora y creadora de su conciencia de mujer de pueblo, y su decisión de seguir viviendo como tal hasta el último día, conectada a los otros como ella.

De lo anterior es elocuente su respuesta más conocida. Está hacia el final del video que registra su entrevista con Madeleine Brumagne para la televisión suiza, al interior del taller que la chilena tuvo en Ginebra:

-Violeta, usted es poeta, músico, borda tapicerías, pinta. Si tuviera que elegir uno de estos medios de expresión, ¿cuál escogería? -Elegiría quedarme con la gente. Son ellos quienes me impulsan a hacer todas estas cosas. ${ }^{29}$

${ }^{28}$ Leonidas Morales, Conversaciones con Nicanor Parra (Santiago: Tajamar Editores, 2006), 157.

${ }^{29}$ García, Violeta Parra, 74. 
La décima llegó de España a Latinoamérica junto con los conquistadores, y se adoptó en las colonias con giros que la enriquecieron con nuevas formas, contenidos y "armados". A un océano de distancia de la Corona, esta forma poética se avivó, se liberó de ciertas constricciones impuestas durante siglos por la poesía culta, y adquirió nuevos rasgos según la región.

Hubo muchas peculiaridades en la décima que comenzó a desarrollarse en Chile hacia el siglo XIX, sobre todo en los campos del Valle Central. Una de ellas fue el rango de temas que abarcó, y que los poetas populares separaron en dos grandes divisiones: el canto «a lo humano» y el canto «a lo divino». Asombra la viveza de ambas categorías. El canto a lo divino alumbró formas que sólo pueden rastrearse en nuestro país, como las décimas para los velorios "del angelito" o los llamados versos "por salutación” y "despedimento". El canto a lo humano es aún más nutrido, con décimas de fundamento para situaciones de todo tipo: "por travesura", "por amor", "por ponderación", "por homenaje", "por el mundo al revés", etcétera.

En esa secuencia figuran también las décimas "por cuerpo repartido", un tipo de composición poética escrita en primera persona, en la que el autor asume el desafío de vincular su propia conformación física a sus conocimientos de geografía. Pocos chilenos tienen noción de esta historia y su clasificación, pero hay un ejemplo de décima por cuerpo repartido que de seguro muchos conocen:

Un ojo dejé en Los Lagos

por un descuido casual, el otro quedó en Parral en un boliche de tragos; recuerdo que mucho estrago de niña vio el alma mía, miserias y alevosías anudan mis pensamientos, entre las aguas y el viento me pierdo en la lejanía.

Mi brazo derecho en Buin quedó, señores oyentes, el otro por San Vicente 
quedó, no sé con qué fin; mi pecho en Curacautín lo veo en un jardincillo, mis manos en Maitencillo saludan en Pelequén, mi falda en Perquilauquén recoge unos pececillos.

Se m'enredó en San Rosendo un pie el cruzar una esquina, el otro en la Quiriquina se me hunde mares adentro, mi corazón descontento latió con pena en Temuco y me ha llorado en Calbuco, de frío por una escarcha, voy y enderezo mi marcha a la cuesta 'e Chacabuco.

Mis nervios dejo en Granero, la sangr'en San Sebastián, y en la ciudad de Chillán la calma me bajó a cero, mi riñonada en Cabrero destruye una caminata y en una calle de Itata se me rompió el estrumento, y endilgo pa' Nacimiento una mañana de plata.

Desembarcando en Riñihue se vio a la Violeta Parra, sin cuerdas en la guitarra, sin hojas en el colihue; una banda de chirigües le vino a dar un concierto; con su hermanito Roberto y Cochepe forman un trío que cant'al orilla del río y en el vaivén de los puertos. 
No es la voz de Violeta Parra la que probablemente viene a la cabeza mientras se leen estos versos suyos. En realidad, son décimas que ella jamás llegó a cantar. Si se ajustaron a una melodía fue porque Patricio Manns las conoció en un cuaderno manuscrito y, maravillado, se propuso musicalizarlas. No llegó a grabarlas sino hasta 1970, y buscó para su composición un título en masculino (y, en su caso, extrañamente premonitorio): "El exiliado del sur". Poco después, y con un cambio en el género del título, el conjunto Inti-Illimani llevó el tema a una audiencia extendida. Es en las voces entrelazadas de José Seves y Jorge Coulon que gran parte de los chilenos guarda este extraño relato en la memoria.

Cuatro años habían pasado desde la muerte de Violeta Parra cuando la fantasía de su cuerpo repartido comenzó a ser tarareada en Latinoamérica. La autora nunca supo que la ficción de sus miembros desperdigados por el territorio se había convertido en canción, aunque Patricio Manns sí alcanzó a contarle sus intenciones pocas semanas antes de su muerte.

- Hay una décima tuya que me gusta mucho, y a la que quiero ponerle música... - - le dijo el cantautor y escritor una mañana de enero de 1967, en la carpa de La Reina.

— ¿Cómo que una? — se ofuscó ella al escucharlo—. ¡Todas deberían gustarte! ${ }^{30}$

La vida de Violeta Parra fue nómade, desde la niñez y casi hasta el final de sus días. Su biografía y su cancionero muestran un constante movimiento, un ir de aquí para allá, “... entre las aguas y el viento / me pierdo en la lejanía".

El fundamento del cuerpo repartido puede leerse en su caso mejor como metáfora que como alegoría. Su vida de viajes fue, primero, el imperativo de una familia obligada a acomodarse a los cambios de trabajo del padre, Nicanor, en sucesivos puestos de profesor primario y otros oficios circunstanciales. Antes de mudarse a Santiago, a los 15 años, Violeta Parra ya había vivido en al menos media decena de casas de varios pueblos del sur de Chile. El matrimonio Parra Sandoval y los nueve niños movían sus pocos bártulos entre casa y casa de campo. San Carlos, Chillán, Villa Alegre, Lautaro (se registra, también, una breve

${ }^{30}$ Entrevista de la autora con Manns. 
estadía en Santiago, hacia 1919, en la pieza de una casona de San Pablo con Manuel Rodríguez).

La raíz no era para ellos un piso de parqué encerado, sino el canto tradicional y la naturaleza del sur. El maqui y los pámpanos de las parras. La máquina de coser de Clarisa, la madre, mujer fuerte, intuitiva y práctica, junto a la que Violeta se quedaba hasta pasada la medianoche estirando costuras. Los juegos junto a los ríos Ñuble y Perquilauquén, las carreras en el estero Las Toscas, la recolección de membrillos a la orilla del Cautín. Las visitas galopando a caballo a las primas Aguilera, en Malloa.

En su casa no había dinero para una vitrola. La música se escuchaba y se aprendía en vivo (Violeta compuso su primera canción a los 9 años de edad: estaba dedicada a su muñeca de trapo).

Más tarde, en su adultez, también su cancionero mostrará puntos geográficos distantes. Hay estrofas que aluden a París y a Chillán, a Arauco y a la pampa argentina; que van o vienen del norte y se agitan con un terremoto en el sur.

"Violeta de los caminos", la llama su hermano Roberto.

En Violeta Parra, el viaje es determinación. Primero, al venirse a Santiago sin haber terminado la escuela ni avisarles a sus padres. La capital está para trabajar, enamorarse, darse a conocer, incluso antes de cumplir los 18. Todo lo asume en un principio a solas y sin un ápice de dudas. "Salí de mi casa un día / pa' nunca retroceder", recuerdan sus décimas autobiográficas. ${ }^{31}$

"De aquí para allá" seguirá su vida, en lo familiar y en lo creativo. Junto a Luis Cereceda, su primer marido, compartió hogar al menos en Puente Alto, Llay Llay, el cerro Los Placeres de Valparaíso (allí nace su hijo Ángel), un cité de la capitalina calle Andes, en el sector de Quinta Normal, y una comunidad formada con sus hermanos Eduardo y Nicanor y sus familias en La Reina. Con Luis Arce, su esposo desde 1949, se estableció un tiempo en calle Catedral, luego en el paradero 22 de la Gran Avenida y más tarde en un sector conocido como Manzanares de San Carlos. La ciudad le reservará más tarde departamentos en Santiago Centro (calle Ejército, avenida España); y en La Reina al menos una casa (calle Segovia) y un terreno para su famosa Carpa (La Cañada 7200), el último hogar, el que acogerá su velorio.

${ }^{31}$ Violeta Parra, Décimas, 135. 
Entre medio, viajes incesantes. En 1952, recorre pueblos mineros del norte junto a una compañía de variedades que ella misma arma, produce y dirige ("Estampas de América"), y en la que embarcó también a su segundo marido, a su hermana Hilda, a un mago, un comediante y unas bailarinas.

El deambular por Europa le exigió similar firmeza de voluntad. Al medio de su primera gira al continente recibió la noticia de la muerte de su hija Rosita Clara. Decidió no volver a Santiago. Era un ritmo incansable, que la autora aceptaba por puro deseo de sobrevivencia y afán de divulgación, y que no le impidió mantenerse constante en la escritura y la composición. Más tarde, óleos y arpilleras viajarían junto a ella.

"Esto lo hago por mí: lo hago por Chile", le decía a su hijo Ángel. ${ }^{32}$ Era un trajín que la excluía como estrella; ajeno su arte por completo a la lógica promocional de quien autogestiona su talento y tasa sus conquistas en medidas de éxito:

- No era a mí a quien aplaudían, porque cuando se canta la canción chilena es a Chile al que se aplaude. ${ }^{33} E P$

32 Entrevista de Ángel Parra con la autora.

${ }^{33}$ García, Violeta Parra, 24. 